\title{
Inside-Out Control of Fc-Receptors
}

\section{Leo Koenderman*}

Department of Respiratory Medicine and Laboratory of Translational Immunology, University Medical Center Utrecht, Utrecht, Netherlands

Receptors recognizing the Fc-part of immunoglobulins (FcR) are important in the engagement of phagocytes with opsonized micro-organisms, but they also play a major role in the pathogenesis of chronic inflammatory diseases. Different FcRs are specifically recognizing and binding the different classes of immunoglobulins, transmitting different signals into the cell. The function of $\lg (F \mathrm{~F} \gamma \mathrm{R}$ 's) and $\lg \mathrm{A}(\mathrm{Fc} \alpha \mathrm{R})$ recognizing receptors is controlled by cellular signals evoked by activation of heterologous receptors in a process generally referred to as inside-out control. This concept is clearly described for the regulation of integrin receptors. Inside-out control can be achieved at different levels by modulation of: (i) receptor affinity, (ii) receptor avidity/valency, (iii) interaction with signaling chains, (iv) interaction with other receptors and (v) localization in functionally different membrane domains. The inside-out control of FcRs is an interesting target for novel therapy by therapeutical antibodies as it can potentiate or decrease the functionality of the response to the antibodies depending on the mechanisms of the diseases they are applied for.

Edited by:

Mark S. Cragg, University of Southampton, United Kingdom

Reviewed by:

Thomas Valerius,

Universitätsklinikum Schleswig-Holstein, Germany Markus Biburger, Friedrich-Alexander-Universität Erlangen-Nürnberg, Germany

*Correspondence: Leo Koenderman I.koenderman@umcutrecht.nl

Specialty section:

This article was submitted to Molecular Innate Immunity, a section of the journal

Frontiers in Immunology

Received: 07 January 2019

Accepted: 28 February 2019

Published: 21 March 2019

Citation:

Koenderman L (2019) Inside-Out

Control of Fc-Receptors.

Front. Immunol. 10:544.

doi: 10.3389/fimmu.2019.00544
Keywords: inside-out control, immunoglobulins, priming, activation, phagocytes, Fc-receptors

\section{INTRODUCTION}

Immunoglobulins have evolved during evolution as a link between the antigen-specific adaptive immunity and the molecular pattern driven innate immune system. These molecules contain an antigen-specific variable region brought about by gene rearrangement in B-cells. The underlying mechanisms for this rearrangement has been reviewed elsewhere (1). For the purpose of this review it suffices to say that this variable part enables specific binding to antigens beyond the common patterns recognized by the innate immune system. After the antibody binds the antigen via the variable regions, the constant region of the immunoglobulins denoted as Fc part can be recognized by other immune cells and facilitate the immune response (2-4).

The Fc-part of immunoglobulins is relevant at three different levels. First of all the Fcpart determines the human (sub)class of the immunoglobulin: IgA (IgA1 and IgA2), IgD, IgE, IgG (IgG1, IgG2a, IgG2b, IgG3, and IgG4) and IgM. During gene rearrangement the B-cell determines, guided by cytokines in its environment, which (sub)class of immunoglobulin is later produced by the respective plasma cells. The second level is the propensity of some classes of immunoglobulins to activate and fixate complement, which greatly enhances the recognition of antigens through recognition of $\mathrm{C} 3 \mathrm{~b}$ and C3bi by complement receptors (CR1/CD35 and CR3/CD11b) on phagocytic cells. The binding of immunoglobulins and complement fragments to antigens is generally referred to as opsonization.

Finally, the third level by which the Fc-part of immunoglobulins is important, is the recognition by specific Fc-receptors. These Fc receptors are mainly expressed by effector cells of the innate immune response [for excellent reviews see (2-7)]. 
Every class of immunoglobulins has specific receptors that can recognize these subclass specific Fc portions. These receptors are indicated by Greek letters: Fc $\gamma$ R for IgG, Fc $\alpha$ R for IgA, FceR for IgE, $\mathrm{F} c \delta \mathrm{R}$ of $\operatorname{IgD}$ and $\mathrm{F} c \mu \mathrm{R}$ for IgM. Apart from these receptors also the neonatal FcR ( $\mathrm{FcRn})$ is expressed by stromal cells and is involved in transfer of immunoglobulins from blood to the tissue (8). Some of the immunoglobulins have more receptors with various affinities for the different subclasses as IgG comes in 5 subclasses (IgG1, IgG2a, IgG2b, IgG3, and IgG4) and IgA in two (IgA1 and IgA2). The situation with IgA is even more complex as the molecules are found as both monomers and dimers, and on mucosal surfaces as dimers with a J-chain and secretory component. The latter form of IgA is referred to as secretory IgA, which can still be recognized by $\mathrm{Fc} \alpha \mathrm{R}(2,3)$. However, additional receptors for the secretory component can modify the binding characteristics of secretory IgA (9).

The FcRs are under tight control as the immune system should evoke a balanced response to invading micro-organisms as well as to signals that can lead to aberrant activation of the immune system such as seen in chronic inflammatory disease including autoimmune disorders (10). Too much activation leads to collateral damage to the host tissue, whereas too little activation can lead to infections. The control of the function of the FcRs is the subject of this review.

\section{FC-RECEPTOR FUNCTIONING IN THE INNATE IMMUNE RESPONSE}

The best known function of FcRs is their role in phagocytosis and killing of opsonized targets. Phagocytosis refers to the process of specialized cells of the immune system that can engulf and take up targets into intracellular organelles called phagosomes (11). These phagosomes are closed and do not have any link with the extracellular milieu. In these organelles the cells can induce a very hostile environment by which the phagocytosed target is killed. This is mediated by multiple processes: fusion of granules filled with cytotoxic proteins, enzymes and peptides, production of toxic oxygen intermediates by a membrane bound NADPHoxidase, and a lowering of the $\mathrm{pH}$ in the phagosome (12).

The fusion of the granules with the phagosome is often referred to as degranulation. This fusion of the phagosome with the granules leads to the formation of so-called phagolysosomes in which the actual killing of microbes takes place. Degranulation is not only into these phagolysomes, but occurs also by fusion of the granules with the plasma membrane. Then the cytotoxic components are liberated into the extracellular space, where they are involved in killing of the targets outside the cell. It will be clear that this extracellular process comes with a cost: damage to the healthy host tissues (13). This process of extracellular killing is also employed by eosinophils and macrophages killing large multicellular targets such as helminths; targets several times larger than the immune cells. Patnode et al. (14) describe clear swarming behavior of eosinophils interacting with helminths that leads to a "together we are strong" type of killing. There is a clear synergism in killing mediated by degranulation and the activation of the NADPH-oxidase; the other major mechanism involved in killing of micro-organisms by phagocytes (15).

It will be clear from the above that FcRs are very important in the interaction of the host with pathogens. This review will focus on two classes of FcRs as these are important in phagocytosis and killing of micro-organisms: $F c \gamma R$ and FcaR. Six genes encode Fc $\gamma$ R's in humans: Fc $\gamma$ RI (CD64), Fc $\gamma$ RIIA (CD32A), Fc $\gamma$ RIIB (CD32B), Fc $\gamma$ RIIC (CD32C), Fc $\gamma$ RIIIA (CD16A), and Fc $\gamma$ RIIIB (CD16B) (4). These receptors are expressed by various immune cells in different combinations and have different affinities for the different IgG subclasses (4). There are several IgA receptors: Fc $\alpha \mathrm{RI}$ (CD89), transferrin-receptor-1 (CD71), asialoglycoprotein-receptor (ASGPR/), Fc $\alpha / \mu \mathrm{R}, \mathrm{FcRL} 4$, and DCSIGN/SIGNR1 (2). However, the best studied in the context of immune function and phagocytosis is Fc $\alpha$ RI (CD89) and, therefore, we will focus on this IgA-receptor in this review.

\section{Signal Transduction}

Signal transduction of FcRs has been studied in detail and reviewed by Bournazos et al. (16). In short, broadly three modules of signaling are found for these receptors: (1) Direct signaling by the receptor itself (CD32s), (2) Via an accessory common FcR $\gamma$-chain (CD64 and CD16A and CD89), and (3) indeterminate signaling because of the absence of an intracellular tail [Glycosylphosphatidylinisotol (GPI) anchored CD16B].

\section{Direct Signaling}

Direct signaling by CD32 is mediated by immunoreceptor tyrosine-based activation motif (ITAM/CD32A and CD32C) (17) and by immunoreceptor tyrosine-based inhibitory motif (ITIM/CD32B) (18). These motifs determine whether the receptors are activating or inhibitory. It is important to emphasize that signaling starts by cross-linking of the receptor leading to activation of phosphatases such as SHP and SHIP, and members of the src-family of tyrosine kinases (19-21). This leads to phosphorylation of the important tyrosine residues in the ITAM/ITIM motifs from where various signaling cascades are initiated. Phosphorylation of ITAMs lead to activation of the cells (22), whereas phosphorylation of ITIMs lead to cell inhibition (23). The mechanisms involved in the control of CD32B have been excellently reviewed by Getahun and Cambier (24).

\section{Signaling via an Accessory Common FcR $\gamma$-Chain}

Signaling via an accessory common $\mathrm{FcR} \gamma$-chain is also mediated by ITAM motifs present in the $\gamma$-chain. Here the main signaling is not mediated by the intracellular tail of the $\mathrm{FcR}$ itself, but by the $\mathrm{FcR} \gamma$-chain that is associated with the receptor. This mode of action is found for CD16A, CD64, and CD89. Similar signals are initiated compared to direct signaling from the receptor (25-27).

\section{Indeterminate Signaling}

Indeterminate signaling seems to be the characteristic of CD16B expressed at high levels on human neutrophils. This receptor lacks both an intra-cellular portion and a transmembrane domain as it linked with the membrane with a GPI-linkage (28). However, it is likely too simple to consider this receptor as 
signaling dead. Various studies indicate that cross-linking CD16B evokes signaling characterized by e.g., changes in intracellular free $\mathrm{Ca}^{2+}\left(\left[\mathrm{Ca}^{2+}\right]_{\mathrm{i}}\right)(29)$. The general idea is that cross-linking leads to an engagement with other receptors that in turn activate a signaling cascade. The identity of such a receptor in CD16B signaling remains to be defined, but studies indicate that integrins and integrin associated proteins might be candidates(30). Such mechanism in trans can also be part of signaling through the other signaling FcRs $(30,31)$. This paradigm will be discussed in more detail later in the review.

Most of the IgG and IgA receptors exhibit a low or intermediate affinity for their monovalent ligands with an exception for Fc $\gamma$ RI/CD64 that has a high affinity for monomeric IgG. The low affinity receptors do not bind to monomeric ligand or this binding is so low affinity that it is difficult to determine in vivo (32). The consequence of this low affinity is that these receptors only bind to multivalent ligand such as found in immune complexes as well as Ig coated surfaces such as found on opsonized micro-organisms(3). This in contrast to Fc $\gamma$ RI that is always bound to IgG, but that interestingly does not lead to appreciable signaling (33).

An additional mode of control of FcRs is the multimerisation of the receptor into clusters at the cell membrane by which their valency increases (34). Modulation of this valency is a means by which the cell can facilitate the interaction with Ig-coated surface.

\section{THE CONCEPT OF INSIDE-OUT CONTROL}

\section{The Concept of Inside-Out Control Identified in Integrin Function}

The concept of inside-out control of immune receptors was first put forward for the function of integrins (35). It basically refers to an increase in receptor affinity, valency and/or function induced by intracellular signals initiated by heterologous stimuli. A very clear example is the finding that a mutation of the Kindlin-3 gene in patients with leukocyte adhesion deficiency III leads to a complete block in the functionality of $\beta 2$ chain containing integrins LFA-1, Mac-1 and p150.95 (36). The genes and expression of these receptors are normal, but functionality is lacking leading to a clinical phenotype reminiscent of LAD1 where the $\beta 2$-chain (CD18) gene is mutated and expression of the CD18 integrins is absent (37). A similar situation is found for the fibrinogen receptor $(\alpha \mathrm{IIb} / \beta 3)$ that is dysfunctional in these Kindlin-3 deficient patients. The molecular mechanisms underlying inside-out control of integrins is excellently reviewed by the group of Ginsberg et al. $(35,38)$.

\section{Inside-Out Control of FcR}

Next to integrins various studies show that also Fc $\gamma$ R's and Fc $\alpha R$ are subjected to inside-out control (39-43). In contrast to integrins where a consensus is present that this mechanism is important, this concept has not yet been generally accepted for FcR function. The main problem with the latter receptors is that many immune cells express multiple FcRs for the same ligand Ig which makes the study of individual receptors difficult. The studies that have focused on inside-out control of specific FcRs have either been performed with cells endogenously expressing only a single Fc-receptor or cell models dependent on cytokines exogenously expressing single Fc-receptors (39-42, 44).

\section{Fc $\gamma$ RII}

An excellent cell to study the inside-out control of Fc $\gamma$ RIIA is the human eosinophil. This cell isolated from the blood of healthy control only expresses this Fc $\gamma$ R. Early work showed that eosinophils carefully isolated in a non-primed fashion hardly bind beads coated with human IgG while they clearly express Fc $\gamma$ RII as visualized in FACS based assays (42). Short term pre-incubation with cytokines such as IL-5 and GM-CSF or chemotaxins such as platelet-activating factor (PAF) lead to clear binding of the cells to these Ig-coated particles, whereas the expression of the receptor on the cell surface was unaltered. This model also allowed the manipulation with different pharmacological inhibitors to find out which signaling models are important in this inside-out control (44). These experiments identified that the MEK-MAP-kinase based signaling in these cells is important as MEK inhibitors clearly block the interaction of pre-activated eosinophils with Ig-coated particles (44). These findings basically imply that different cytokines differentially engaging different signaling pathways can steer the inside-out control of FcyRII: those that engage MEK-MAPK such as IL-5 steer the function of Fc $\gamma$ RII, whereas those that more engage PI$3 \mathrm{~K}$ and p38 such as IL-4 more activate Fc $\alpha \mathrm{R}$ [see below and (44)]. Similar experiments are very difficult to perform with neutrophils because of the high co-expression of Fc $\gamma$ RIII (CD16B). It should be emphasized that Huizinga et al. have shown that Fc $\gamma$ RII is also the main signaling IgG-receptor in neutrophils (45) and most likely controlled by a similar signaling module as operational for Fc $\alpha \mathrm{R}$ (42). However, direct experimental proof is lacking. Interestingly, Aleman et al. (46) described the importance of Fc $\gamma$ RIIIB in netosis of neutrophils supporting the concept of Fc $\gamma$ RIIIB as a signaling receptor.

\section{Fc $\alpha$ RI}

This receptor is expressed by multiple immune cells including eosinophils. It is, however, important to mention that Fc $\alpha$ RI on eosinophils is heavily glycosylated and behaves differently in SDS-PAGE gels when compared with the receptor present in e.g., neutrophils (47). Comparable with serum-IgG coated beads, only (cytokine) primed eosinophils interact with IgA-coated beads (44). However, for $\mathrm{F} c \alpha \mathrm{R}$ mediated interaction between IgAcoated targets and primed eosinophils the PI-3-kinase signaling pathway is important. This has important consequences as cytokines such as IL-4 that primarily engage this pathway without apparent activation of the MAP-kinase pathway only induce binding of eosinophils with IgA coated targets and not IgG coated targets (44). Interaction with IgG coated beads is not sensitive for (cytokine) priming, likely because Fc $\gamma$ RIIIB that is highly expressed by neutrophils can facilitate the interaction with IgG coated beads.

These findings have consequences in vivo as differential priming with different mediators at different times and places will determine whether innate immune cells will engage with opsonized particles. It is important to emphasize that eosinophils isolated from patients with allergic diseases exhibit a primed 
phenotype with respect to binding to IgG and IgA coated beads (48). This implies that these cells have engaged with Th2 driven cytokines and other mediators leading to long term priming of the cells as the primed phenotype persisted during the whole isolation procedure ex vivo. Thus, the FcRs retain their primed phenotype for a long time in vitro. The situation in vivo is less clear as the group of Chilvers et al. put forward the hypothesis that part of the primed phenotype of granulocytes associated with primed FcRs deprimes in the lung in vivo $(49,50)$. This concept, however, has been tested for neutrophils but not for eosinophils. The expression of multiple FcRs on neutrophils precludes a simple testing of the hypothesis that depriming leads to deactivated FcRs on granulocytes.

The mechanisms underlying inside-out control are multiple, complex and cross-interacting. They can be at the level of the receptor itself, associated signaling partner molecules, clustering of homologous and heterologous receptors allowing activation in trans and last but not least changes in organization of plasma membrane specialized areas such as lipid rafts and caps.

The functionality of FcRs expressed on the plasma membrane can be accomplished at different levels: (1) changes in valency (multiple receptors are engaged by multivalent ligands on opsonized surfaces (see Figure 1), and (2) changes in affinity of single receptors for their ligands.

The valency of receptors is very important as the consensus in the field is that cross-linking of receptors by multiple ligands on the opsonized surface is the main trigger for activation through FcRs (34). It is generally believed that tyrosine kinases binding the one $\mathrm{FcR}$ cross-phosphorylate tyrosine residues in ITAM's/ITIM's of the adjacent FcRs. This then initiates the signaling cascades leading to the activation of the downstream functions. So these receptors have to come together in order to be able to signal. Cross-linking by itself seems to be sufficient for signaling as artificial cross-linking by receptor antibodies leads to phosphorylation of the receptors and induction of signaling $(29,51)$. However, artificial cross-linking does not completely recapitulate the activation induced by natural ligand. This is nicely illustrated by the finding that cross-linking of Fc $\gamma$ RIIIB (CD16B) that does not have any intracellular tail leads to changes in intracellular free $\mathrm{Ca}^{2+}\left(\left[\mathrm{Ca}^{2+}\right]_{\mathrm{i}}\right)$ whereas no signaling motif is present in this receptor. Although it might be that cross-linking of Fc $\gamma$ RIIIB engages Fc $\gamma$ RIIA through the Fc-portion of the CD16 antibody. In addition, such changes in $\left[\mathrm{Ca}^{2+}\right]_{\mathrm{i}}$ are not necessarily induced by natural ligand in the form of immune complexes (45) or serum-opsonized particles (52). Thus, caution should be taken to apply artificial crosslinking of the receptor as surrogate for FcR signaling. It is also difficult to test the hypothesis that an increase in valency (receptor clustering) is sufficient for FcR signaling as it is difficult to accomplish this without additionally affecting the receptor affinity for its ligand.

The affinity of low-affinity receptors for their ligands is difficult to determine as monomeric ligand does not bind with sufficient affinity even after inside-out activation. This makes sense as the immune system ideally does not want to interact with monomeric Ig's in blood and mucosal tissues. Therefore, it is very difficult to study valency and affinity of FcRs as two
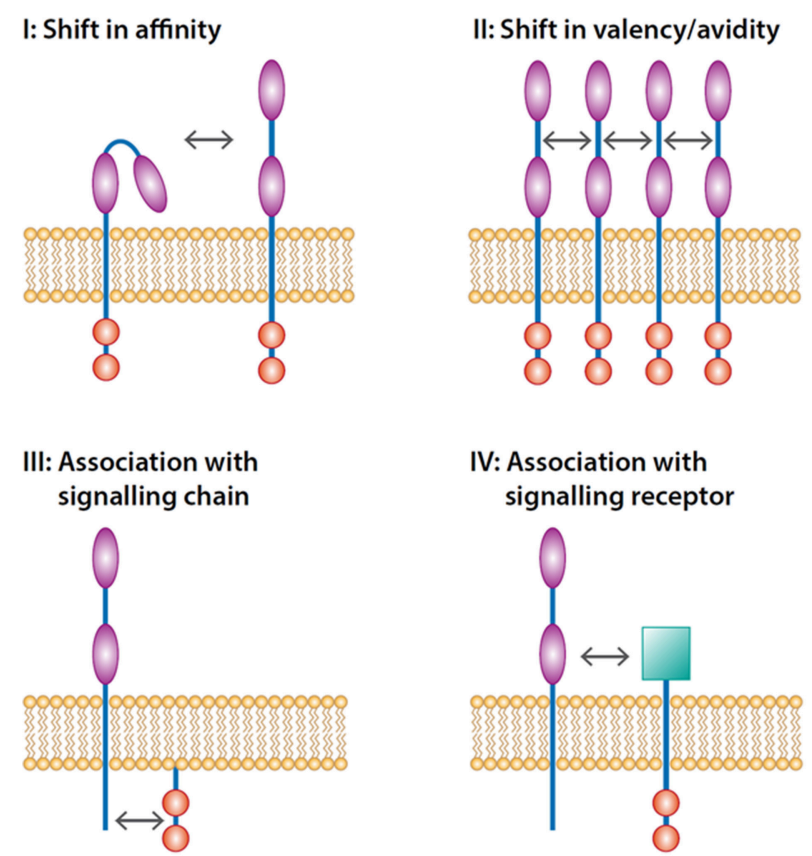

FIGURE 1 | Levels of inside-out control of FcRs . Inside-out control can be accomplished at four levels. The first level is modulation of affinity of single receptors opening up the binding domain(s) of the immunoglobulin domains (illustrated by facilitating the activation of the receptor which in turn signals through signaling motifs (illustrated by $\mathbf{0}$ ) present in the receptor. The second level is induction of lateral movement of the receptor increasing the valency of the receptor. The third level is the interaction with signaling chains such as FcR $\gamma$-chain that transmit the signal-tranduction pathways. The fourth level is the trans-activation through an associated heterologous signaling receptor (illustrated by

independent mechanisms and, therefore, the functionality of $\mathrm{FcR}$ in the remainder of this review is the resultant of both increased valency and affinity.

\section{THE IMPORTANCE OF THE INTRACELLULAR TAIL OF FcRs IN INSIDE-OUT CONTROL}

In order for inside-out control to be affecting the functionality of FcRs these signals should converge at the intracellular tail of the FcRs such as also found for integrins (38). This concept is studied in more molecular detail for two FcRs: Fc $\alpha$ RI (CD89) and Fc $\gamma$ RI (CD64) $(39-41,53,54)$.

\section{The Importance of Serine263 in the Intracellular Tail of Fc $\alpha$ RI}

Initial studies indicated that several kinases, PI-3-kinase, MAP kinase and p38 were critically involved in the activation of the functionality of FcaRI $(40,41,48)$. This was found both in primary cells (leukocytes) as well as cell lines ectopically expressing this receptor. Inhibitors of these kinases modulated the activation FcaRI even in the absence of the accessory 
common Fc $\gamma$-chain. This implies that phosphorylation is involved in the direct control of the functionality of Fc $\alpha$ RI. However, there were no clear consensus motifs present in the intracellular tail that are preferentially phosphorylated by any of these kinases. In depth analysis of the receptor led to the conclusion that $\mathrm{F} c \alpha \mathrm{RI}$ expressed in resting cells was constitutively phosphorylated and thus that kinase activity was already found in the cytosol of resting cells (41). This led to the concept that Fc $\alpha$ RI is actively suppressed in its function by constitutive phosphorylation of the receptor. By studying FcaRI receptor mutants transfected into cytokine-dependent $\mathrm{Ba} / \mathrm{F} 3$ cells it was found that a serine residue at the 263 position in the intracellular tail is essential for the functionality of Fc $\alpha R I$ in the context of binding to IgA-coated beads. Mutation of the serine residue to alanine led to a constitutively active receptor supporting the concept that an active kinase is important in keeping the receptor in a non-functional state. This hypothesis was supported by the finding that the $\mathrm{S}>\mathrm{D}$ mutation, introducing a negative charge at the 263 position, lead to a non-functional receptor as if it was constitutively phosphorylated (41).

Ten Broeke et al. recently provided evidence that the identity of this constitutively active kinase is glycogen synthase kinase- 3 (GSK-3) (43), a kinase that is constitutively active in resting cells such as leukocytes and its activity is inhibited by phosphorylation (43). Interestingly, such phosphorylation can be mediated by cytokine-induced activation of the PI-3K and protein kinase-

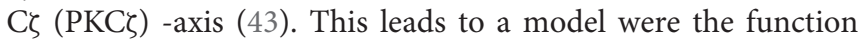
of Fc $\alpha$ RI is actively suppressed by phosphorylation by GSK3 in unactivated cells. Cytokine-induced activation of PI-3K followed by activation of PKC $\zeta$ leads to phosphorylation and inactivation of GSK-3. This in turn leads to dephosphorylation and activation of Fc $\alpha$ RI. It is still unclear at which level the control of dephosphorylating of the receptor is achieved. It might be that a constitutive active phosphatase dephosphorylates the receptor or that such enzyme is actively controlled by inside out signals such as found for Fc $\gamma$ RI (39). Unfortunately, a similar concept has not been developed in any detail for the inside-out control of Fc $\gamma$ RII.

\section{Mechanism of Inside-Out Control of Fc $\gamma$ RI (CD64) Functionality: The Tail and Importance of Phosphatase Activity}

The situation is different with $\mathrm{Fc} \gamma \mathrm{RI}$ as this is a high affinity receptor able to bind to monomeric IgG. The general idea is that this receptor is always occupied by ligand under conditions such as found in the plasma. Nonetheless, several indications in studies by the group of Leusen et al. (55) provided evidence that this receptor irrespective of bound monomeric IgG can still bind to immune complexes. Only this latter binding is sensitive for inside-out control. The receptor ectopically expressed in hematopoietic cell lines is sensitive for inside-out signaling. The concept arising from this study is that the phosphatase PP2A is the driving enzyme involved in dephosphorylating the receptor and thereby activating its functionality (39). Here again the phosphorylated receptor has a low functionality and dephosphorylation leads to activation. The underlying mechanisms are not yet completely understood, but recently Brandsma et al. have described that inside-out control of Fc $\gamma$ RI is at least in part mediated by lateral movement of the receptor in the membrane (54). It is tempting to speculate that this modulation of movement will be important for the control of valency of this receptor.

\section{The Intracellular Tail and the Inside-Out Control of FcyRII (CD32)}

The importance of the intracellular tail of Fc $\gamma$ RII comes from experiments in cell lines showing that ectopically expressing tailless version of $\mathrm{Fc} \gamma \mathrm{RIIA} / \mathrm{B}$ is accompanied by a blunted signaling response (17). To test the hypothesis that the tail of FcyRIIA is also important in phagocytes Clark et al. (56) transduced neutrophils with a cell permeant peptide encompassing the intracellular tail of Fc $\gamma$ RIIA. They could show that this peptide decreased $\mathrm{Ca}^{2+}$ signaling as well as formation of phagolysosomes in human neutrophils.

It is clear that the intracellular tails of Fc $\gamma$ RIIA/B, Fc $\gamma$ RIIIA, and $\mathrm{Fc} \alpha \mathrm{RI}$ are important for signaling. However, tail-less mutants co-expressed with other receptors such as integrins are still able to transmit signals indicating the intimate cross-talk between these receptors and alternative signaling chains (57).

\section{INSIDE-OUT CONTROL AND RECEPTOR INTERACTIONS}

The view that only valency and affinity are important for the inside-out function of Fc-receptors is too simple. The complexity of the ligands (uni/multi valent, fixed complement etc.), immune complexes and opsonized microbes, is very relevant. Here additional proteins and other ligands are present/expressed that can bind to a multitude of additional receptors on innate effector cells e.g., integrins, Toll-like receptors, glucan receptors, complement receptors etc. It is to be expected that differential inside-control mechanisms will control some if not all of these receptors. It will be clear that the net result of all these interactions will lead to a very complex situation that is difficult to understand from the view of individual receptor function.

\section{Fc $\gamma$ R/Fc $\gamma R$ Cross-Talk}

Most innate effector cells express multiple FcRs and most multiple Fc $\gamma$ R's. Monocytes and macrophages express Fc $\gamma$ RI, Fc $\gamma$ RII, and Fc $\gamma$ RIII, neutrophils Fc $\gamma$ RIIA and Fc $\gamma$ RIIIB. Eosinophils only express Fc $\gamma$ RIIA and maybe Fc $\gamma$ RIIB/C. Crosstalk between Fc $\gamma$ RII and Fc $\gamma$ RIIIA/B has been suggested by various experiments. Co-crosslinking of Fc $\gamma$ RIIA and Fc $\gamma$ RIIIB leads to a clear activation of neutrophils characterized by changes in $\left[\mathrm{Ca}^{2+}\right]_{\mathrm{I}}$ and downstream functions (29). On NK-cells Fc $\gamma$ RIIA and Fc $\gamma$ RIIIA cross-modulate their functions (58). It is tempting to speculate that subtle changes in inside-out control of these individual receptors will influence the end result of co-activation.

\section{FcR-Integrin Cross-Talk}

Several studies have shown that the interaction of primary cells expressing both integrin receptors and FcRs with opsonized targets is characterized by a clear cross-talk $(30,59-61)$. Again 
this is best shown in cells that express relatively little different FcRs to exclude interference of above mentioned Fc $\gamma R / F c \gamma R$ interactions. Again eosinophils are an interesting cell model as they only express Fc $\gamma$ RIIA as activating Fc $\gamma$ R. It has clearly been shown that a synergism is present when a surface is expressing integrin ligands such C3bi (ligand of Mac-1/CR3) together with Ig's. Van der Bruggen et al. have shown that yeast opsonized with both ligands is superior when compared with yeast only coated with Ig's or complement (60). However, a trivial explanation might be that the affinity/avidity of the opsonin receptors might be higher when both ligands are present.

Ortiz-Stern et al. have described the importance of crosslinking of Fc $\gamma$ RIIIB on neutrophils in modulation of $\beta 1$-integrins whereas cross-linking of Fc $\gamma$ RIIA and Fc $\gamma$ RIIIb both lead to activation of $\beta 2$-integrins (62). More of this type of cross-talk between FcRs and integrins has been reviewed by this group (59). Relevant for this concept is the finding that a genetic polymorphism in the Fc $\gamma \mathrm{RIIIb}$ gene affects the interaction of this receptor with Fc $\gamma$ RIIA and Mac-1/CR3 (CD11b/CD18) (63).

\section{FcR-TLR Cross-Talk}

Apart from functional interactions between opsonin and integrin receptors, the function of FcRs is also modulated by multiple other receptors. An important class are the pattern recognition receptors such as toll-like receptors. These receptors can engage with FcR signaling by physical interaction as well as through signaling after ligand binding (64). Indeed, coimmunoprecipitation studies in murine neutrophils have shown that TLR4 (LPS-receptor) physically interacts with Fc $\gamma$ RIII upon binding to its ligand LPS (64). It is good to emphasize that there are marked differences in FcRs and Toll-like receptors between mouse and man $(4,65)$.

For cross-talk between FCR and TLR both receptors do not need to physically interact as the main signaling pathways induced by TLR activation, NFKb, MAP-kinases and PI-3 kinase, are important in inside-out control of Fc $\gamma$ RIIA and Fc $\alpha$ RI. More of these interactions between FcR and TLR have been excellently reviewed recently (66).

\section{Inside Control of FcRs by Other Receptors or Signaling Molecules}

Apart from TLR's there is a whole range of cytokine/chemokine receptors and glucan receptors that all have in common that they engage in signaling pathways important for inside-out control of FcRs. It will be clear that these signals control the interaction between innate effector cells and their targets. This mechanism has been known for a long time and was generally referred to as priming: a process that does not induce a certain cell function by itself but greatly enhances this response to a (heterologous) agonist (67). Particularly, cytotoxic responses are sensitive for such priming responses that act as "safety locks" to prevent aspecific activation of inflammatory cells. Part of such a priming response is mediated by the interaction of FcRs with function modulating membrane proteins.

Not many membrane receptors/chains other than FcR- $\gamma$ chain, additional FcRs or integrins have been described to be involved in the functionality of FcRs. The correct expression of FcRs is dependent on the presence of $\beta-2$ (CD18) integrins. Kindzelskii et al. have described the aberrant capping responses of membrane proteins including Fc $\gamma$ RIII and the urokinase receptor in patients with leukocyte adhesion deficiency I (LADI) (68). The data imply that a physical cross talk between integrins and FcRs is part of the correct functioning of FcRs (57). The reverse has not been published.

Next to these aforementioned binding partners periplakin has been implicated in the regulation of function of Fc $\gamma$ RI (69). The authors described that periplakin was important in receptor recycling as well as ligand affinity. Periplakin has also been implicated in the control of G-protein coupled receptors, which might important for the signaling of FcR in trans (70) (see below).

\section{INSIDE-OUT CONTROL AND GLYCOSYLATION OF FC-RECEPTORS AND IMMUNOGLOBULINS}

In recent years another concept of inside-out control has emerged. It turned out that differences in glycosylation of Fcreceptors has a major impact on their functionality as has recently been reviewed by Hayes et al. (71). This mode of control is nicely illustrated by Patel et al. (72) showing that the function of FcyRIIIA on NK-cells is dependent on its glycan composition. This implies that post-translational processing of FcR is of importance for their functionality on the cell membrane (73). It is not only the glycosylation of FcRs that is important, but also the glycosylation of the different Ig's as large differences are found between the functionality of certain Ig's depending on their N-glycan content $(74,75)$. Interestingly, also anti-inflammatory characteristics of IgG can be attributed to differences in glycosylation (76). In conclusion, by affecting glycosylation of both FcRs as well as Ig's immune cells can steer the immune response. This has major consequences for designing therapeutical antibodies (77).

\section{INSIDE-OUT CONTROL AND SIGNALING IN TRANS}

As mentioned before FcRs can signal through their intracellular tail and/or through an accessory FcR $\gamma$ chain constitutively associated with the receptor. A third mechanism is activation in trans through heterologous receptors associated with the FcRs only after (pre)activation. This concept of signaling in trans has been identified many years ago for signaling through G-protein coupled receptors directly activating growth factor receptors such as the EGF receptor (78). This mode of transactivation between receptors seems important for FcRs. Several interesting interactions have been published.

\section{FcRs and Other FcRs}

Most of the data regarding transactivation of FcRs to other FcRs is indirect. Nevertheless, several lines of evidence show that co-crosslinking of different FcRs leads to differences in signaling. Vossebeld et al. showed that co-crosslinking Fc $\gamma$ RII and Fc $\gamma$ RIII lead to more mobilization of intracellular free $\mathrm{Ca}^{2+}$ 
(29). This study also implied a function for Fc $\gamma$ RIII as this PI-linked protein was still able to modulate signaling through Fc $\gamma$ RIIA. Other studies have shown that cross-linked FcRs lead to differences in the activation of the MAPkinase signaling pathways $(20,79)$. Interestingly, co-crosslinking of FcRs leads to differential of adhesive phenotypes dependent on the type of FcR and their polymorphisms (80). This mechanism might be important in the fine tuning of responses of leukocytes with different immune complexes. A next level of complexity comes from studies showing functional antagonistic behavior of Fc $\gamma$ RIIA and Fc $\gamma$ RIIIB (81). These authors provided evidence that immune complexes that are endocytosed by Fc $\gamma$ RIIIB are cleared that is considered as anti-inflammatory whilst this process mediated by Fc $\gamma$ RIIA leads to Netosis that is considered to be pro-inflammatory. These studies imply that subtle changes brought about by inside out signaling determines the type of the immune response.

\section{FcRs and Integrins}

Most data on FCR signaling in trans is through integrins. Many studies imply that FcRs pair with different integrins upon activation with immune complexes or by crosslinking of the receptors by anti-receptor antibodies. However, these experiments in primary cells that cannot be genetically manipulated are difficult to interpret in terms of receptor specific signaling as there will be interplay between these receptors, and other modulating membrane receptors where it is basically impossible to determine which signal originates from which signaling chain. To circumvent these "chicken and the egg" issues experiments have been performed in cell lines ectopically expressing FcRs and integrins. Poo et al. have described the physical interaction between Fc $\gamma$ RIII and Mac1 (CD11b) in fibroblasts (82). A similar finding described the interaction between Fc $\gamma$ RII and Mac-1 (57). This latter interaction is important for Fc $\gamma$ RII mediated phagocytosis. Indirect experiments show that these interactions are also important in the response of neutrophils with opsonized particles (83). The concept that Mac-1 can transduce signals for other Mac-1 binding partners has been described before (84).

\section{The Interaction Between FcRs and G-Protein Coupled Receptors (GPCR)}

The interaction between FcRs and G-protein coupled receptors (GPCR) can cross regulate their functions. It has been established that the function of Fc $\gamma$ RII on eosinophils is upregulated by priming evoked by agonists of GPCR (67). However, it is uncertain whether a physical interaction between Fc $\gamma$ RII and GPCR is necessary or that the activated GPCR activates the receptor by cytosolic signaling. Relevant is, however, that periplakin that regulates the functionality of Fc $\gamma \mathrm{RI}$ (CD64) can also bind GPCR's (70) supporting a potential bridging role of periplakin between FcRs and GPCR's. Such functions have been amply described in the control of integrins, which has been recently reviewed by Ye et al. (38).

\section{FcRs With Other Proteins}

FcRs with other proteins have been described but one should be aware of the fact that the intimate interaction between integrins and FcRs might preclude the identification of other binding partners: in multimolecular complexes these proteins such as integrin associated protein (85) or thrombospondin (86) might bind to integrins rather than the associated FcR.

\section{INSIDE-OUT CONTROL, MEMBRANE DOMAINS, AND LATERAL MOVEMENT}

Up to now the functionality of FcRs has been described as if the receptors are free flowing in the plane of the plasma membrane. This is, however, a too simple view as the membrane is organized in domains with different fluidities. Best studied are the micro domains rich in cholesterol also referred to as lipid rafts (87). But other specialized domains such as found in the lamellipodium (88) and uropods (89) are also characterized as being enriched in important receptors and signaling molecules. Receptors can therefore be localized at different membrane compartments that are relatively slowly interacting. Not much is known regarding the distribution of FcRs in these different domains, but recent studies support the importance of lateral mobility of FcRs in the plain of the membrane and the importance of colocalization in these domains (54). In addition, Ten Broeke et al. provided evidence that dephosphorylation of Fc $\alpha$ RI and functional activation of the receptor is associated with enhanced lateral movement of the receptor and possibly an increase in valency of the receptor (43). Moreover, data of Yang et al. implied that cross-linking of Fc $\gamma$ RIIIb (CD16b) leads to lipid raft mediated activation of SHP2 (51).

\section{INSIDE-OUT CONTROL AND THE HIGH AFFINITY RECEPTOR FOR IGE, FC $\varepsilon$ RI}

The main emphasis in this review was inside-out control of IgG and IgA receptors as this process was best described in this context. However, several studies clearly indicate that also the function of FceRI is controlled by inside-out signals. This control has been excellently reviewed by Kraft and Kinet (90). Important for this review is the requirement of expression of the tetraspanin CD63 for optimal functionality of FceRI on mast cells (91). As CD63 is expressed in granules this finding links degranulation with an optimal function of FceRI. Several other processes are involved in the control of FceRI by either activating (92) or inhibiting the receptor (93). These processes are now seen as therapeutic targets in allergic diseases (6).

\section{THE IMPLICATIONS OF INSIDE-OUT CONTROL IN CLINICAL APPLICATIONS OF HUMANIZED ANTIBODIES}

The implications of FCR inside-out control for the treatment of patients with clinical humanized antibodies are just emerging. The approach will obviously depend on the requirement of 
effector cells in such therapy and the FcR that they express. Treatment with blocking antibodies directed against single molecules (such as cytokines, complement fragments, and chemokines) might not be directly affected by inside-out control of FcRs as these receptors do not have an obvious role here. However, FcRs play a role in clearance of these target-antibody complexes as the majority is cleared by endocytosis and will subsequently be degraded in the lysosomal compartment (53). This may indicate that therapeutic antibodies might be more rapidly cleared in patients with inflammatory diseases that are characterized by the presence of priming mediators in the peripheral blood or tissue (94). Under these conditions inhibition of inside-out control might be a therapeutic target as it might preserve therapeutic doses of these antibodies allowing lower dosing of the antibodies.

The situation with several antibodies might be more complex. Particularly, those antibodies blocking the function of cellular receptors are of interest. On the one hand, one might want to inhibit inside-out control for preservation of sufficient therapeutical concentrations (see above) on the other insideout activation might be beneficial for the clinical effect. The idea behind this conception is the following. Anti-receptor antibodies or antibodies directed against cell bound cytokines not only block these molecules, but they might also enable the cell expressing these proteins to be killed (95). This is mediated by antibody or complement dependent cytotoxicity: ADCC or CDC, respectively. Binding of antibodies and/or complement to cells leads to opsonization. Phagocytic receptors are particularly directed against multivalent ligands such as a surface covered with antibodies or complement. The phagocytes will then activate the same armamentarium normally employed for the killing of micro-organisms. The result is a cytotoxic response toward the opsonized cell instead of micro-organism. As both complement receptors such as complement receptor 3 (CR3/Mac-1/CD11b) and FcRs such as Fc $\gamma$ RIIA (CD32) and Fc $\alpha$ RI (CD89) are very sensitive for inside-out activation it will be clear that this activation is very important for the clinical action $(53,84)$. Not much is known regarding these issues in humans in vivo some studies now imply that ADCC is often important for the clinical effect of therapeutic antibodies $(96,97)$. A clear example is the anti-IL5R antibody, Benralizumab, which functions through ADCC (95) of IL5R $\alpha+$ cells [eosinophils,

\section{REFERENCES}

1. Nussenzweig MC. Immune receptor editing: revise and select. Cell. (1998) 95:875-8. doi: 10.1016/S0092-8674(00)81711-0

2. Mkaddem SB, Christou I, Rossato E, Berthelot L, Lehuen A, Monteiro RC. IgA, IgA receptors, and their anti-inflammatory properties. Curr Top Microbiol Immunol. (2014) 382:221-35. doi: 10.1007/978-3-319-07911-0_10

3. Monteiro RC, Van De Winkel JGJ. IgA Fc receptors. Annu Rev Immunol. (2003) 21:177-204. doi: 10.1146/annurev.immunol.21.120601.141011

4. Ravetch J, Bolland S. IgG Fc receptor. Annu Rev Immunol. (2001) 19:275-90. doi: 10.1146/annurev.immunol.19.1.275

5. Hargreaves CE, Rose-Zerilli MJJ, Machado LR, Iriyama C, Hollox EJ, Cragg MS, et al. Fc $\gamma$ receptors: genetic variation, function, and disease. Immunol Rev. (2015) 268:6-24. doi: 10.1111/imr.12341 basophils and possibly ILC2 (98)]. The concept of inside-out activation of the ADCC under these conditions has not been applied to these clinical studies.

The overall conclusion whether or not inside-out control should be considered in augmenting the therapeutic is likely to be dependent on the mode(s) of action of the therapeutic antibodies. It is, however, clear that this complexity should be considered gaining optimal therapeutic effectiveness of current and new antibodies.

\section{CONCLUSION}

Inside-out control of FcRs as well as integrins functions as a safety lock preventing collateral damage evoked by innate immune effector cells. Here a clear cross-talk is present between the adaptive immune response producing priming mediators and the innate immune system that adapt to these signals. Part of the priming mediators liberated during inflammation leads to inside-out control of FcRs potentiating these receptors. This very complex mechanism is based on modulation of valency of the receptors, their affinity, their interaction with other signaling chains and receptors and their localization in specialized membrane areas such as lipid rafts. The many levels of control will make it possible to fine tune the inside out control with therapeutic molecules only affecting part of this process. This will allow stratified therapy such that the therapeutic effect is maximal while the normal function of phagocytes is preserved.

\section{AUTHOR CONTRIBUTIONS}

The author confirms being the sole contributor of this work and has approved it for publication.

\section{FUNDING}

This work was supported by Universitair Medisch Centrum Utrecht.

\section{ACKNOWLEDGMENTS}

Dr. N. Vrisekoop is thanked for critically reading the manuscript.
6. MacGlashan Jr DW. IgE-dependent signaling as a therapeutic target for allergies. Trends Pharmacol Sci. (2012) 33:502-9. doi: 10.1016/j.tips.2012.06.002

7. Monteiro RC. Role of $\operatorname{IgA}$ and IgA fc receptors in inflammation. $J$ Clin Immunol. (2010) 30:1-9. doi: 10.1007/s10875-009-9338-0

8. Roopenian DC, Akilesh S. FcRn: the neonatal Fc receptor comes of age. Nat Rev Immunol. (2007) 7:715-25. doi: 10.1038/nri2155

9. Lamkhioued B, Gounni AS, Gruart V, Pierce A, Capron A, Capron M. Human eosinophils express a receptor for secretory component. Role in secretory IgA-dependent activation. Eur J Immunol. (1995) 25:117-25. doi: $10.1002 /$ eji.1830250121

10. Karsten CM, Köhl J. The immunoglobulin, IgG Fc receptor and complement triangle in autoimmune diseases. Immunobiology. (2012) 217:1067-79. doi: 10.1016/j.imbio.2012.07.015 
11. Gordon S. Phagocytosis: an immunobiologic process. Immunity. (2016) 44:463-75. doi: 10.1016/j.immuni.2016.02.026

12. Segal AW. How neutrophils kill microbes. Annu Rev Immunol. (2005) 23:197223. doi: 10.1146/annurev.immunol.23.021704.115653

13. Bardoel BW, Kenny EF, Sollberger G, Zychlinsky A. The balancing act of neutrophils. Cell Host Microbe. (2014) 15:526-36. doi: 10.1016/j.chom.2014.04.011

14. Patnode ML, Bando JK, Krummel MF, Locksley RM, Rosen SD. Leukotriene $\mathrm{B}_{4}$ amplifies eosinophil accumulation in response to nematodes. J Exp Med. (2014) 211:1281-8. doi: 10.1084/jem.20132336

15. Yazdanbakhsh M, Tai PC, Spry CJ, Gleich GJ, Roos D. Synergism between eosinophil cationic protein and oxygen metabolites in killing of schistosomula of Schistosoma mansoni. J Immunol. (1987) 138:3443-7.

16. Bournazos S, Wang TT, Dahan R, Maamary J, Ravetch JV. Signaling by antibodies: recent progress. Annu Rev Immunol. (2017) 35:285-311. doi: 10.1146/annurev-immunol-051116-052433

17. Van den Herik-Oudjik IE, Capel PJA, van der Bruggen T, Van den Winkel JGJ. Identification of signaling motifs within human Fc $\gamma$ RIIa and Fc $\gamma$ RIIb isoforms. Blood. (1995) 85:2202-11.

18. Roghanian A, Stopforth RJ, Dahal LN, Cragg MS. New revelations from an old receptor: immunoregulatory functions of the inhibitory $\mathrm{FC}$ gamma receptor, Fc $\gamma$ RIIB (CD32B). J Leukoc Biol. (2018) 103:1077-88. doi: 10.1002/JLB.2MIR0917-354R

19. Huang Z, Hunter S, Kim M-K, Indik ZK, Schreiber AD. The effect of phosphatases SHP-1 and SHIP-1 on signaling by the ITIM- and ITAMcontaining Fc $\gamma$ receptors Fc $\gamma$ RIIB and Fc $\gamma$ RIIA. J Leukoc Biol. (2003) 73:8239. doi: 10.1189/jlb.0902454

20. Rollet-Labelle E, Gilbert C, Naccache PH. Modulation of human neutrophil responses to CD32 cross-linking by serine/threonine phosphatase inhibitors: cross-talk between serine/threonine and tyrosine phosphorylation. J Immunol. (2000) 164:1020-8. doi: 10.4049/jimmunol.164.2.1020

21. Sato K, Ochi A. Superclustering of B cell receptor and FC gamma RIIB1 activates Src homology 2-containing protein tyrosine phosphatase-1. J Immunol. (1998) 161:2716-22.

22. Underhill DM, Goodridge HS. The many faces of ITAMs. Trends Immunol. (2007) 28:66-73. doi: 10.1016/j.it.2006.12.004

23. Verbrugge A, Meyaard L. Signaling by ITIM-bearing receptors. Curr Immunol Rev. (2005) 1:201-12. doi: 10.2174/1573395054065160

24. Getahun A, Cambier JC. Of ITIMs, ITAMs, and ITAMis: revisiting immunoglobulin Fc receptor signaling. Immunol Rev. (2015) 268:66-73. doi: $10.1111 /$ imr.12336

25. Morton HC, Van Den Herik-Oudijk IE, Vossebeld P, Snijders A, Verhoeven AJ, Capel PJA, et al. Functional association between the human myeloid immunoglobulin A Fc receptor (CD89) and FcR gamma chain: molecular basis for CD89/FcR gamma chain association. J Biol Chem. (1995) 270:297817. doi: 10.1074/jbc.270.50.29781

26. Van Vugt MJ, Heijnen IA, Capel PJ, Park SY, Ra C, Saito T, et al. FcR gammachain is essential for both surface expression and function of human $\mathrm{FC}$ gamma RI (CD64) in vivo. Blood. (1996) 87:3593-99.

27. Wirthmueller BU, Kurosaki T, Murakami MS, Ravetch JV, Wirthmueller U. Signal transduction by Fc gamma RIII (CD16) is mediated through the gamma chain. J Exp Med. (1992) 175:1381-90. doi: 10.1084/jem.175.5.1381

28. Huizinga TW, van der Schoot CE, Jost C, Klaassen R, Kleijer M, von dem Borne AE, et al. The PI-linked Fc gamma RIII is released on stimulation of neutrophils. Nature. (1988) 333:667-9. doi: 10.1038/333667a0

29. Vossebeld PJM, Kessler J, Von dem Borne AEGK, Roos D, Verhoeven AJ. Heterotypic Fc $\gamma$ R clusters evoke a synergistic Ca2+response in human neutrophils. J Biol Chem. (1995) 270:10671-9. doi: 10.1074/jbc.270.18.10671

30. Petty HR, Worth RG, Todd RF. Interactions of integrins with their partner proteins in leukocyte membranes. Immunol Res. (2002) 25:75-95. doi: $10.1385 /$ IR:25:1:75

31. Reumaux D, Kuijpers TW, Hordijk PL, Duthilleul P, Roos D. Involvement of $\mathrm{F} c \gamma$ receptors and $\beta 2$ integrins in neutrophil activation by anti-proteinase- 3 or anti-myeloperoxidase antibodies. Clin Exp Immunol. (2003) 134:344-50. doi: 10.1046/j.1365-2249.2003.02280.x

32. van de Winkel JG, van Ommen R, Huizinga TW, de Raad MA, Tuijnman WB, Groenen PJ, et al. Proteolysis induces increased binding affinity of the monocyte type II FcR for human IgG. J Immunol. (1989) 143:571-8.
33. Hulett MD, Hogarth PM. The second and third extracellular domains of Fc $\gamma$ RI (CD64) confer the unique high affinity binding of IgG2a. Mol Immunol. (1998) 35:989-96. doi: 10.1016/S0161-5890(98)00069-8

34. Ortiz DF, Lansing JC, Rutitzky L, Kurtagic E, Prod'homme T, Choudhury A, et al. Elucidating the interplay between IgG-Fc valency and $F c \gamma$ R activation for the design of immune complex inhibitors. Sci Transl Med. (2016) 8:365ra158. doi: $10.1126 /$ scitranslmed.aaf9418

35. Faull RJ, Ginsberg MH. Inside-out signaling through integrins. J Am Soc Nephrol. (1996) 7:1091-7.

36. Kuijpers TW, Van De Vijver E, Weterman MAJ, De Boer M, Tool ATJ, Van Den Berg TK, et al. LAD-1/variant syndrome is caused by mutations in FERMT3. Blood. (2009) 113:4740-6. doi: 10.1182/blood-2008-10-182154

37. Springer TA. Inherited deficiency of the Mac-1, LFA-1, p150,95 glycoprotein family and its molecular basis. J Exp Med. (1984) 160:1901-18. doi: 10.1084/jem.160.6.1901

38. Ye F, Kim C, Ginsberg MH. Molecular mechanism of insideout integrin regulation. J Thromb Haemost. (2011) 9:20-5. doi: 10.1111/j.1538-7836.2011.04355.x

39. Bakema JE, Bakker A, de Haij S, Honing H, Bracke M, Koenderman L, et al. Inside-out regulation of Fc RI (CD89) depends on PP2A. J Immunol. (2008) 181:4080-8. doi: 10.4049/jimmunol.181.6.4080

40. Bracke M, Nijhuis E, Lammers JJ, Coffer PJ, Koenderman L. A critical role for PI 3-kinase in cytokine-induced Fc alpha -receptor activation. Blood. (2000) 95:2037-43.

41. Bracke M, Lammers JWJ, Coffer PJ, Koenderman L. Cytokine-induced insideout activation of Fc $\alpha \mathrm{R}$ (CD89) is mediated by a single serine residue (S263) in the intracellular domain of the receptor. Blood. (2001) 97:3478-83. doi: 10.1182/blood.V97.11.3478

42. Koenderman L, Hermans SW, Capel PJ, van de Winkel JG. Granulocytemacrophage colony-stimulating factor induces sequential activation and deactivation of binding via a low-affinity IgG Fc receptor, hFc gamma RII, on human eosinophils. Blood. (1993) 81:2413-9.

43. ten Broeke T, Honing H, Brandsma A, Jacobino S, Bakema J, Kanters D, et al. FcalphaRI dynamics are regulated by GSK-3 and PKCzeta during cytokine mediated inside-out signaling. Front Immunol. (2018) 9:3191. doi: 10.3389/fimmu.2018.03191

44. Bracke M, Coffer PJ, Lammers JW, Koenderman L. Analysis of signal transduction pathways regulating cytokine-mediated Fc receptor activation on human eosinophils. J Immunol. (1998) 161:6768-74.

45. Huizinga TW, van Kemenade F, Koenderman L, Dolman KM, von dem Borne AE, Tetteroo PA, et al. The $40-\mathrm{kDa} F \mathrm{~F}$ gamma receptor (FcRII) on human neutrophils is essential for the IgG-induced respiratory burst and IgG-induced phagocytosis. J Immunol. (1989) 142:2365-9.

46. Alemán OR, Mora N, Cortes-Vieyra R, Uribe-Querol E, Rosales C. Differential use of human neutrophil Fc $\gamma$ receptors for inducing neutrophil extracellular trap formation. J Immunol Res. (2016) 2016:1-17.doi: 10.1155/2016/ 2908034

47. Monteiro RC, Hostoffer RW, Cooper MD, Bonner JR, Gartland GL, Kubagawa H. Definition of immunoglobulin A receptors on eosinophils and their enhanced expression in allergic individuals. J Clin Invest. (1993) 92:1681-5. doi: 10.1172/JCI116754

48. Bracke M, van De Graaf E, Lammers JW, Coffer PJ, Koenderman L. In vivo priming of FcalphaR functioning on eosinophils of allergic asthmatics. J Leukoc Biol. (2000b) 68:655-61. doi: 10.1189/jlb.68.5.655

49. Kitchen E, Rossi A, Condliffe A, Haslett C, Chilvers E. Demonstration of reversible priming of human neutrophils using platelet- activating factor. Blood. (1996) 88:4330-7.

50. Summers C, Chilvers ER, Michael Peters A. Mathematical modeling supports the presence of neutrophil depriming in vivo. Phys Rep. (2014) 2:e00241. doi: $10.1002 /$ phy2.241

51. Yang H, Jiang H, Song Y, Chen DJ, Shen XJ, Chen JH. Neutrophil CD16b crosslinking induces lipid raft-mediated activation of SHP-2 and affects cytokine expression and retarded neutrophil apoptosis. Exp Cell Res. (2018) 362:121-31. doi: 10.1016/j.yexcr.2017.11.009

52. Koenderman L, Tool ATJ, HooyBrink B, Roos D, Hansen CA, Williamson $\mathrm{JR}$, et al. Adherence of human neutrophils changes $\mathrm{Ca} 2+$ signaling during activation with opsonized particles. FEBS Lett. (1990) 270:49-52. doi: 10.1016/0014-5793(90)81232-D 
53. Brandsma AM, Jacobino SR, Meyer S, ten Broeke T, Leusen JHW. Fc receptor inside-out signaling and possible impact on antibody therapy. Immunol Rev. (2015) 268:74-87. doi: 10.1111/imr.12332

54. Brandsma AM, Schwartz SL, Wester MJ, Valley CC, Blezer GLA, Vidarsson $\mathrm{G}$, et al. Mechanisms of inside-out signaling of the high-affinity IgG receptor Fc $\gamma$ RI. Sci Signal. (2018) 11:eaaq0891. doi: 10.1126/scisignal.aaq0891

55. Van Der Poel CE, Karssemeijer RA, Boross P, Van Der Linden JA, Blokland M, Van De Winkel JGJ, et al. Cytokine-induced immune complex binding to the high-affinity IgG receptor, Fc $\gamma$ RI, in the presence of monomeric IgG. Blood. (2010) 116:5327-33. doi: 10.1182/blood-2010-04-280214

56. Clark AJ, Petty HR. A cell permeant peptide containing the cytoplasmic tail sequence of $\mathrm{Fc}$ receptor type IIA reduces calcium signaling and phagolysosome formation in neutrophils. Cell Immunol. (2010) 261:153-8. doi: 10.1016/j.cellimm.2009.12.002

57. Worth RG, Mayo-Bond L, van de Winkel JG, Todd 3rd RF, Petty HR. CR3 (alphaM beta2; CD11b/CD18) restores IgG-dependent phagocytosis in transfectants expressing a phagocytosis-defective Fc gammaRIIA (CD32) tail-minus mutant. J Immunol. (1996) 157:5660-5.

58. Arase N, Arase H, Park SY, Ohno H. Association with FcR gamma is essential for activation signal through NKR-P1 (CD161) in Natural Killer (NK) cells and NK1.1 + T Cells. J Exp Med. (1997) 186:1957-63. doi: 10.1084/jem.186.12.1957

59. Ortiz-Stern A, Rosales C. Cross-talk between Fc receptors and integrins. Immunol Lett. (2003) 90:137-43. doi: 10.1016/j.imlet.2003.08.004

60. van der Bruggen T, Kok PT, Raaijmakers JA, Lammers JW, Koenderman L. Cooperation between Fc gamma receptor II and complement receptor type 3 during activation of platelet-activating factor release by cytokine-primed human eosinophils. J Immunol. (1994) 153:2729-35.

61. Worth RG, Kim M-K, Kindzelskii AL, Petty HR, Schreiber AD. Signal sequence within FCRIIA controls calcium wave propagation patterns: apparent role in phagolysosome fusion. Proc Natl Acad Sci USA. (2003) 100:4533-8. doi: 10.1073/pnas.0836650100

62. Ortiz-Stern A, Rosales C. Fc $\gamma$ RIIIB stimulation promotes $\beta 1$ integrin activation in human neutrophils. J Leukoc Biol. (2005) 77:787-99. doi: $10.1189 / \mathrm{jlb} .0504310$

63. Urbaczek AC, Toller-Kawahisa JE, Fonseca LM, Costa PI, Faria CMQG, Azzolini AECS, et al. Influence of Fc $\gamma$ RIIIb polymorphism on its ability to cooperate with FcrRIIa and CR3 in mediating the oxidative burst of human neutrophils. Hum Immunol. (2014) 75:785-90. doi: 10.1016/j.humimm.2014.05.011

64. Rittirsch D, Flierl MA, Day DE, Nadeau BA, Zetoune FS, Sarma JV, et al. Crosstalk between TLR4 and Fc $\gamma$ ReceptorIII (CD16) pathways. PLoS Pathog. (2009) 5:e1000464. doi: 10.1371/journal.ppat.1000464

65. Rehli M. Of mice and men: species variations of toll-like receptor expression. Trends Immunol. (2002) 23:375-8. doi: 10.1016/S1471-4906(02)02259-7

66. van Egmond M, Vidarsson G, Bakema JE. Cross-talk between pathogen recognizing toll-like receptors and immunoglobulin $\mathrm{Fc}$ receptors in immunity. Immunol Rev. (2015) 268:311-27. doi: 10.1111/imr.12333

67. Coffer PJ, Koenderman L. Granulocyte signal transduction and priming: cause without effect? Immunol Lett. (1997) 57:27-31. doi: 10.1016/S0165-2478(97)00067-9

68. Kindzelskii AL, Xue W, Todd 3rd RF, Boxer LA, Petty HR. Aberrant capping of membrane proteins on neutrophils from patients with leukocyte adhesion deficiency. Blood. (1994) 83:1650-5.

69. Beekman JM, Bakema JE, van de Winkel JGJ, Leusen JHW. Direct interaction between FcgammaRI (CD64) and periplakin controls receptor endocytosis and ligand binding capacity. Proc Natl Acad Sci USA. (2004) 101:10392-7. doi: 10.1073/pnas.0401217101

70. Milligan G, Murdoch H, Kellett E, White JH, Feng GJ. Interactions between G-protein-coupled receptors and periplakin: a selective means to regulate G-protein activation. Biochem Soc Trans. (2004) 32:878-80. doi: 10.1042/BST0320878

71. Hayes JM, Wormald MR, Rudd PM, Davey GP. Fc gamma receptors: glycobiology and therapeutic prospects. J Inflamm Res. (2016) 9:209-19. doi: $10.2147 /$ JIR.S121233

72. Patel KR, Roberts JT, Subedi GP, Barb AW. Restricted processing of CD16a/Fc receptor IIIa N-glycans from primary human NK cells impacts structure and function. J Biol Chem. (2018) 293:3477-89. doi: 10.1074/jbc.RA117.001207
73. Oliva KD, Cavanaugh JM, Cobb BA. Antibody receptors steal the sweet spotlight. J Biol Chem. (2018) 293:3490-1. doi: 10.1074/jbc.H118.001955

74. Dekkers G, Rispens T, Vidarsson G. Novel concepts of altered immunoglobulin G galactosylation in autoimmune diseases. Front Immunol. (2018) 9:553. doi: 10.3389/fimmu.2018.00553

75. Quast I, Peschke B, Lünemann JD. Regulation of antibody effector functions through IgG Fc N-glycosylation. Cell Mol Life Sci. (2017) 74:837-47. doi: 10.1007/s00018-016-2366-z

76. Nimmerjahn F, Böhm S, Kao D. Sweet and sour: the role of glycosylation for the anti-inflammatory activity of immunoglobulin G. Curr Top Microbiol Immunol. (2014) 382:393-417. doi: 10.1007/978-3-319-07911-0_18

77. Jennewein MF, Alter G. The immunoregulatory roles of antibody glycosylation. Trends Immunol. (2017) 38:358-72. doi: 10.1016/j.it.2017.02.004

78. Voisin L, Foisy S, Giasson E, Lambert C, Moreau P, Meloche S. EGF receptor transactivation is obligatory for protein synthesis stimulation by G protein-coupled receptors. Am J Physiol Physiol. (2002) 283:C446-55. doi: 10.1152/ajpcell.00261.2001

79. Sánchez-Mejorada G, Rosales C. Signal transduction by immunoglobulin Fc receptors. J Leukoc Biol. (1998) 63:521-33. doi: 10.1002/jlb.63.5.521

80. Jakus Z, Berton G, Ligeti E, Lowell CA, Mocsai A. Responses of neutrophils to anti-integrin antibodies depends on costimulation through low affinity Fc Rs: full activation requires both integrin and nonintegrin signals. J Immunol. (2004) 173:2068-77. doi: 10.4049/jimmunol.173.3.2068

81. Chen K, Nishi H, Travers R, Tsuboi N, Martinod K, Wagner DD, et al Endocytosis of soluble immune complexes leads to their clearance by Fc $\gamma$ RIIIB but induces neutrophil extracellular traps via Fc $\gamma$ RIIA in vivo. Blood. (2012) 120:4421-31. doi: 10.1182/blood-2011-12-401133

82. Poo H, Krauss JC, Mayo-Bond L, Todd RF, Petty HR. Interaction of Fc receptor type IIIB with complement receptor type 3 in fibroblast transfectants: evidence from lateral diffusion and resonance energy transfer studies. $\mathrm{J} \mathrm{Mol}$ Biol. (1995) 247:597-603. doi: 10.1016/S0022-2836(05)80141-X

83. Koenderman L, Van Der Bruggen T, Kok PT, Raaijmakers JA, Lammers JW. Cooperation Between Fc Gamma Receptor II and Complement Receptor Type 3 During Activation of Platelet-Activating factor release by cytokine-primed human eosinophils. (2018). Available online at: http://www.jimmunol.org/ content/153/6/2729

84. Van Spriel AB, Leusen JHW, Van Egmond M, Dijkman HBPM, Assmann KJM, Mayadas TN, et al. Mac-1 (CD11b/CD18) is essential for Fc receptormediated neutrophil cytotoxicity and immunologic synapse formation. Blood. (2001) 97:2478-86. doi: 10.1182/blood.V97.8.2478

85. Schwartz MA, Brown EJ, Fazeli B. A $50-\mathrm{kDa}$ integrin-associated protein is required for integrin-regulated calcium entry in endothelial cells. J Biol Chem. (1993) 268:19931-4.

86. Chung J, Gao AG, Frazier WA. Thrombspondin acts via integrin-associated protein to activate the platelet integrin alpha(IIb)beta3. J Biol Chem. (1997) 272:14740-6. doi: 10.1074/jbc.272.23.14740

87. Lingwood D, Simons K. Lipid rafts as a membrane-organizing principle. Science. (2010) 327:46-50. doi: 10.1126/science.1174621

88. Swaney KF, Huang C-H, Devreotes PN. Eukaryotic chemotaxis: a network of signaling pathways controls motility, directional sensing, and polarity. Annu Rev Biophys. (2010) 39:265-89. doi: 10.1146/annurev.biophys.093008. 131228

89. Hind LE, Vincent WJB, Huttenlocher A. Leading from the back: the role of the uropod in neutrophil polarization and migration. Dev Cell. (2016) 38:161-9. doi: 10.1016/j.devcel.2016.06.031

90. Kraft S, Kinet JP. New developments in FceRI regulation, function and inhibition. Nat Rev Immunol. (2007) 7:365-78. doi: 10.1038/nri2072

91. Kraft S, Jouvin M-H, Kulkarni N, Kissing S, Morgan ES, Dvorak $\mathrm{AM}$, et al. The tetraspanin CD63 is required for efficient IgE-mediated mast cell degranulation and anaphylaxis. J Immunol. (2013) 191:2871-8. doi: 10.4049/jimmunol.1202323

92. Kuehn HS, Beaven MA, Ma HT, Kim MS, Metcalfe DD, Gilfillan AM Synergistic activation of phospholipases $C \gamma$ and $C \beta$ : A novel mechanism for PI3K-independent enhancement of FceRI-induced mast cell mediator release. Cell Signal. (2008) 20:625-36. doi: 10.1016/j.cellsig.2007.11.016

93. Sabato V, Verweij MM, Bridts CH, Levi-Schaffer F, Gibbs BF, De Clerck LS, et al. CD300a is expressed on human basophils and seems to inhibit 
IgE/FceRI-dependent anaphylactic degranulation. Cytom Part B Clin Cytom. (2012) 82:132-8. doi: 10.1002/cyto.b.21003

94. Mukherjee M, Lim HF, Thomas S, Miller D, Kjarsgaard M, Tan B, et al. Airway autoimmune responses in severe eosinophilic asthma following lowdose Mepolizumab therapy. Allergy Asthma Clin Immunol. (2017) 13:2. doi: 10.1186/s13223-016-0174-5

95. Ghazi A, Trikha A, Calhoun WJ. Benralizumab - a humanized mAb to IL$5 \mathrm{R} \alpha$ with enhanced antibody-dependent cell-mediated cytotoxicity - a novel approach for the treatment of asthma. Expert Opin Biol Ther. (2012) 12:113-8. doi: $10.1517 / 14712598.2012 .642359$

96. Choudary KB. Monoclonal antibodies with ADCC and CDC enhancement for therapy. Int J Pharma Bio Sci. (2013) 4:B588-99.

97. Strohl WR. Current progress in innovative engineered antibodies. Protein Cell. (2018) 9:86-120. doi: 10.1007/s13238-017-0457-8
98. Smith SG, Chen R, Kjarsgaard M, Huang C, Oliveria JP, O’Byrne PM, et al. Increased numbers of activated group 2 innate lymphoid cells in the airways of patients with severe asthma and persistent airway eosinophilia. J Allergy Clin Immunol. (2016) 137:75-86.e8. doi: 10.1016/j.jaci.2015.05.037

Conflict of Interest Statement: The author declares that the research was conducted in the absence of any commercial or financial relationships that could be construed as a potential conflict of interest.

Copyright (c) 2019 Koenderman. This is an open-access article distributed under the terms of the Creative Commons Attribution License (CC BY). The use, distribution or reproduction in other forums is permitted, provided the original author $(s)$ and the copyright owner(s) are credited and that the original publication in this journal is cited, in accordance with accepted academic practice. No use, distribution or reproduction is permitted which does not comply with these terms. 